\title{
Overview of MARPOL ANNEX VI regulations for prevention of air pollution from marine diesel engines
}

\author{
Leo Čampara ${ }^{1}$, Nermin Hasanspahić ${ }^{2}$, and Srđan Vujičićc ${ }^{3}$ \\ ${ }^{1} \mathrm{PhD}$ student, University of Dubrovnik; Maritime Department, Ćira Carića 4, 20000 Dubrovnik, Croatia, \\ ${ }^{2} \mathrm{PhD}$ student, University of Dubrovnik; Maritime Department, Ćira Carića 4, 20000 Dubrovnik, Croatia, \\ ${ }^{3} \mathrm{PhD}$ student, University of Dubrovnik; Maritime Department, Ćira Carića 4, 20000 Dubrovnik, Croatia,
}

\begin{abstract}
Increased international awareness of growing global air pollution issues resulted in adoption of measures necessary to reduce ships' emissions into the atmosphere. The MARPOL convention with 1997 Protocol amendments included a new Annex VI which for the first time regulates harmful compounds emitted from ships on international voyages. The Parties of the 1997 Protocol have incorporated the MARPOL convention regulations within their own national legislation., An International Air Pollution Prevention (IAPP) certificate is issued to ships flying their flag by a recognized organization/classification society. The IAPP certificate serves as proof of a ship's compliance with these regulations, thus assuring a ships' seaworthiness. This paper summarises the most important provisions of Annex VI as applied to air pollutants from marine diesel engines, namely nitrogen and sulphur oxides, particulate matter and carbon dioxide. Recent studies proved that once adopted, Annex VI regulations have positive effect on the reduction of air pollution from ships. The Annex VI regulations present a major challenge and obligation to stakeholders in the shipping industry. Marine diesel engines are the most common choice to propel merchant ships compared with competitive alternatives. Engine manufacturers are particularly affected, as these regulations have necessitated the development of cleaner marine diesel engines and additional innovative technological solutions.
\end{abstract}

\section{Introduction}

Over the last three decades, large industrial plants and road vehicles have been regarded as the major sources of air pollutants, while ships were unjustifiably considered too mobile, too far from the coast and insufficiently important to be given significant attention as sources of air pollution. While harmful emissions from land-based sources have gradually been regulated and reduced, the continuous increase in maritime traffic, which presently accounts for more than $90 \%$ of total world trade, has led to a greater contribution to global air pollution [1]. This has resulted in an increasing awareness of ships' negative environmental impact which has forced the shipping industry to considerably reduce emissions with the aim of preserving the sea, the environment in general and the health of all living beings [1].

Although most of the harmful exhaust emissions from ships engaged in international voyages end up being widely distributed throughout all seas, a number of research conducted by non-governmental environmental organizations have shown that ships are still the largest individual source of acidity and eutrophication of the European land environment. Also, due to the density and frequency of maritime traffic, ships significantly contribute to the elevated level of particles hazardous to health and to the destruction of the ozone layer. To illustrate this, annual emissions from internationally trading ships into the seas surrounding Europe ${ }^{1}$ were estimated to contain 3.3 million tons of nitrogen oxides (NOx), 2.3 million tonnes of sulphur oxides $\left(\mathrm{SO}_{\mathrm{x}}\right)$, and 250,000 tons of harmful particulate matter (PM) [2]. Ships' SOx and NOx emissions is estimated to increase by around $40-50 \%$ between the years 2000 and 2020 . If true, Europe's emissions from ships involved in international shipping will reach or even exceed the total emissions from land based sources in all 27 EU member states by the year 2020 [2]. However, according to the latest estimation by the European Monitoring and Evaluation Programme (EMEP), the annual NOx reduction in the Baltic Sea area will be 22,000 tons as result of the newly IMO designated Baltic and North Sea NOx Emission Control Areas (ECA) [3]. A number of recent studies also estimated that international shipping accounts for $14-31 \%, 4-10 \%$ and $2-3 \%$ of the total worldwide global emissions of $\mathrm{NOx}, \mathrm{SOx}$, and $\mathrm{CO}_{2}$, respectively. These estimates take into account emissions increasing by a factor of four as the number of ships might triple by 2050 [4]. The IMO third greenhouse gas emission study foresees that despite a predicted increase in ships' average efficiency of $40 \%$, and in the absence of any further regulations, $\mathrm{CO}_{2}$ emissions from international shipping could increase between $50-250 \%$ by 2050 [5]. These figures depend on future economic growth and energy developments.

\footnotetext{
${ }^{1}$ The Baltic Sea, the North Sea, the North-East Atlantic, the Mediterranean and the Black Sea.
} 
The exhausts of propulsion and auxiliary marine diesel engines are primarily responsible for a ships' air pollution. Approximately $90 \%$ of large merchant ships, i.e. tankers, bulk carriers, container ships, etc., are propelled by large two stroke slow speed diesel engines, while all of them have at least one diesel generator installed on board [6]. Although very reliable, efficient, relatively easy and economical to maintain, they must currently comply with the increasingly stringent regulations on emissions of exhaust gasses pollutants [7].

This paper provides a brief overview of the most important and currently enforced International Maritime organisation $^{2}$ (IMO) regulations as applied to the prevention and limitation of harmful substances contained in the exhaust gases of marine diesel engines, as stipulated in the MARPOL Convention ${ }^{3}$ Annex VI [8, 9, 10]. These regulations have a direct impact on the operational management of ships, particularly those engaged in international voyages. This paper mainly focuses on regulations concerning emissions of NOx, SOx and PM which are considered to be the major air pollutants from ships, including carbon dioxide $\left(\mathrm{CO}_{2}\right)$ which is the main contributor of excessive greenhouse gas formation. Although not a focus of this paper, it is important to note that in addition to aforementioned regulations on marine diesel engines emissions, Annex VI provisions also regulate ozone depleting substances (ODS), volatile organic compounds (VOC), marine fuel oils (MFO) and shipboard incinerators operation, all equally important in controlling air pollution from ships $[8,10]$.

MARPOL Annex VI provisions, described further in the paper, provide guidance for adopting regional and national legislation on air pollution from ships but do not limit Administrations in comprising additional measures in order to enhance them.

\section{A brief history of MARPOL Annex VI main provisions}

Air pollution has currently become one of the most significant worldwide environmental issues. Given the fact that maritime transport has a distinctly international character, knowledge acquired via series of research into air pollution from ships confirmed the urgent necessity to develop international regulations to limit their harmful emissions.

In addition to several Conventions ${ }^{4}$ of general character which are related to air pollution, framework provisions of the United Nations Convention on the Law of the Sea (UNCLOS), generated in the Montego Bay conference in 1982, specifically deal with pollution of the sea and air in Article 212[7]. The Parties to the UNCLOS have been authorised to adopt national regulations for the prevention, reduction and control of marine pollution from the air, or indirectly through the air, while taking into account internationally recognized norms, standards and recommended practices [7]. This has pledged them to apply national legislation and international rules on the prevention of air pollution in the territory under their sovereignty and to vessels flying their flag [7]. Implementations started in countries and regions, primarily in the European Union and the United States, which are close to busy sea routes and who were therefore more exposed to ships' emissions.

As a result of cumulative scientific evidence, the 1980's saw an increased awareness of the impact of ship emissions on the environment and public health. This prompted the IMO to develop and establish new international policy on the prevention of air pollution from ships. At the International Conference of Parties to the MARPOL Convention, held in London from 15 to 26 September 1997, MARPOL Convention was amended with the Protocol of $1997^{5}$ and a new Annex VI, Regulations for the Prevention of Air Pollution from Ships was introduced [10, 11, 12]. The adoption of Annex VI followed years of negotiation between IMO members and stakeholders of the shipping industry. These negotiations which were driven by political and economic interests impeded and delayed the adoption of the new regulations which came into force on 19 May 2005, 12 months after Samoa fulfilled the ratification requirement ${ }^{6}$ of 15 countries which represented at least 50 per cent of the world's gross tonnage (GT) $[13,14]$. The provisions of Annex VI, which are of an international character and which all contracting States adhere to, initially set limits on SOx, NOx and PM emissions from ship

\footnotetext{
${ }^{2}$ The International Maritime Organization (IMO) is a specialized organization of the United Nations based in London, which was initially founded with the purpose of promoting maritime safety. It currently has 173 Member States and three Associate Members representing $99.31 \%$ of the world's merchant shipping tonnage. It was adopted by the United Nations conference in Geneva in 1948 and came into force in 1958 when it was ratified by 21 states. The first name of the organisation was Intergovernmental Maritime Consultative Organization (IMCO) which was changed in 1982 to IMO. In general, the purpose of the organization is to establish and enhance exchange of information and cooperation between governments in maritime issues, to provide assistance and resources in establishing maritime regulations and standards related to the safety of navigation, ships and people, the protection of the marine environment as well as the elimination of discrimination and unnecessary restrictions in achieving agreement on maritime issues.

${ }^{3}$ MARPOL - the International Convention for the Prevention of Pollution from Ships is a fundamental international agreement covering all types of marine environmental pollution by ships due to operational or accidental causes. It was adopted on 2 November 1973 in London and amended by the Protocol of 1978. The combined instrument finally entered into force on 2 October 1983 and is referred to as MARPOL 73/78 Convention. It was significantly amended again by the Protocol of 1997 when a new Annex VI was added and since then it is referred to as the MARPOL Convention. It presently includes six Annex regulations as follows: Annex I - Prevention of Pollution by Oil, Annex II - Control of Pollution by Noxious Liquid Substances in Bulk, Annex III - Prevention of Pollution by Harmful Substances Carried by Sea in Packaged Form, Annex IV - Prevention of Pollution by Sewage from Ships, Annex V - Prevention of Pollution by Garbage from Ships, Annex VI - Prevention of Air Pollution from Ships. Presently, 156 countries representing $99.42 \%$ of the world's merchant shipping tonnage are parties to the MARPOL Convention.

${ }^{4}$ The United Nations Conference on the Human Environment (Stockholm, 1972); The Convention on Long-Range Transboundary Air Pollution (Geneva, 1979) and its seven Protocols; The Vienna Convention for the Protection of the Ozone Layer (Vienna, 1985) and its Montreal Protocol (Montreal 1987); The United Nations Framework Convention on Climate Change (Rio de Janeiro, 1992) and its Kyoto Protocol (Kyoto, 1997).

5 The requirements of the IMO Protocol of 1997 are in accordance with the Montreal Protocol of 1987, as amended in London in 1990 which is an international environmental agreement, held under the auspices of the United Nations under which the participating nations agreed to reduce production and consumption of ozone depleting substances for the ozone layer protection purposes.

${ }^{6}$ A State to become a Party to MARPOL must ratify MARPOL Annexes I and II. The rest of Annexes VI is voluntary as far as membership to MARPOL Convention is concerned, only MARPOL Annexes I and II must be ratified for the State to become a Party to MARPOL Convention.
} 
exhausts, established Emission Control Areas (ECA) with more stringent limits for SOx and NOx, prohibited deliberate emissions of ODS and regulated VOC emissions as well as shipboard incineration [14].

Since Annex VI represented the starting point of the regulation of air pollution from ships, it was to be expected that due to new scientific evidence, implementation experience and technological improvements, that the provisions laid down in the Protocol of 1997 would need to be revised and amended. Therefore, in the following years, a number of resolutions and amendments including new provisions were introduced by the Marine Environment Protection Committee ${ }^{7}$ (MEPC). Revision of Annex VI and Technical Code adopted by MEPC 58 in 2008, came into force on 1 July 2010, was significant progressions in establishing strengthen emission limits $[1,14]$.

Another crucial regulatory step which was taken by the IMO was the inclusion of binding mandatory energy efficiency measures aimed at reducing greenhouse gas emissions from international shipping, primarily $\mathrm{CO}_{2}$, the most significant contributor. Resolution A.963(23) $)^{8}$, adopted by the IMO assembly on the 23 December 2003, initiated the development of these measures by MEPC which finally resulted in the adoption of the related amendments at MEPC 62 in July 2011 when new chapter 4 regulations on the energy efficiency of ships was introduced. This came into force on 1 January $2013[12,15]$. Up to date, Annex VI is ratified by 89 countries, which represents $96.18 \%$ of the world's merchant shipping tonnage $[8]$.

\subsection{Current MARPOL Annex VI general provisions}

The current version of Annex VI comprises five chapters within which there are 26 regulations arranged. Chapter 1 refers to the definitions and the final application of the rules. Chapter 2 provides guidance for the necessary surveys, certification and means of control. Chapter 3 is devoted to requirements on limits and control mechanisms for all emissions from ships except $\mathrm{CO} 2$, which is covered by chapter 4 and its operational and technical energy efficiency measures. Chapter 5 outlines verification of compliance with the provisions of Annex VI during audits [16]. There are currently ten appendices $^{9}$ to Annex VI and 30 various continually developing guidelines provided for the smooth and uniform implementation of the regulations by flag State Administrations and other relevant shipping industry stakeholders [12].

Annex VI applies to all ships, fixed and floating drilling rigs and other platforms, except where specified within specific regulations ${ }^{10}$. Starting on 19 May 2005, internationally trading ships of 400 GT or more, which operate in the waters under the jurisdiction of the States that have ratified Annex VI, or fly their flag, must have an International Air Pollution Prevention certificate ${ }^{11}$ (IAPPC). For ships of less than 400 GT, the flag Administration may establish appropriate measures to comply with the applicable provisions of Annex VI $[16,17]$.

Every ship, as defined by Annex VI, is subjected to an initial survey either before the ship is put into service or before the IAPP Certificate is issued for the first time. Periodic surveys are conducted at intervals specified by the flag Administration, but cannot exceed five years. A minimum of one intermediate survey has to be carried out during the period that the certificate is valid $[16,18]$.

The current Annex VI regulations control and limit the following main areas [12]:

- Emissions of ODS from refrigeration plants and fire fighting equipment (regulation 12)

- NOx emissions from marine diesel engines (regulation 13)

- SOx emissions from ships (regulation 14)

- VOC emissions from oil tankers cargo tanks (regulation 15)

- Shipboard incinerators emissions (regulation 16)

- Marine fuels quality (regulation 18)

- Energy efficiency of ships (chapter 4)

\subsection{Regulation 13 - Nitrogen oxides}

\footnotetext{
${ }^{7}$ The Marine Environment Protection Committee (MEPC) is the IMO's senior technical body on marine pollution related matters. It is responsible for coordinating all IMO's activities related to prevention and control of the environmental pollutions from ships. In the work and decision-making it is assisted by a number of Sub-Committees sometimes shared with the Maritime Safety Committee. Also, the MEPC sets up working groups that deal with various items of its agenda, e.g. ballast water, air pollution, GHG emissions, etc. The Committees and its working groups are supported by the IMO Secretariat that deals with all related administrative aspects.

${ }^{8}$ IMO Policies and Practices Related to the Reduction of Greenhouse Gas Emissions from Ships.

${ }^{9}$ Appendices to Annex VI: Appendix I - Form of IAPP Certificate, Appendix II - Test cycles and weighting factor, Appendix III - Criteria and procedures for designation of Emission Control Areas, Appendix IV - Type approval and operational limits for shipboard incinerators, Appendix V - Information to be included in the Bunker Delivery Note (BDN), Appendix VI - Fuel verification procedure for MARPOL Annex VI, Appendix VII - Emission Control Areas (ECAs), Appendix VIII - Form of International Energy Efficiency (IEE) Certificate Appendix IX - Information to be submitted to the IMO Ship Fuel Oil Consumption database, Appendix X - Form of Statement of Compliance - Fuel Oil Consumption reporting.

${ }^{10}$ Regulations 3, 5, 6, 13, 15, 16, 18, 19, 20,21, 22 and 22A of Annex VI. Regulation 3 generally stipulates that Annex VI regulations shall not apply to any emission necessary for the purpose of securing the safety of a ship and saving a life at sea, or any emission resulting from damage to a ship or its equipment provided that all reasonable precautions have been taken after a damage occurred.

${ }^{11}$ The International Air Pollution Prevention certificate (IAPPC) is a document certifying ship's compliance with technical and operational requirements of Annex VI after an initial or renewal survey. It is valid for five years and is issued by the flag State Administration or by recognised organization, i.e. classification society. The certificate shall be issued in the form and content corresponding to the form of appendix 1 to Annex VI.
} 
Regulation 13 limits $\mathrm{NOx}^{12}$ emissions from all MDEs with a power output of more than $130 \mathrm{~kW}$ which are installed on ships constructed, i.e. keel laid, on or after the 1 January 2000[7, 19]. It also applies to engines of the same power which are subject to "major conversion ${ }^{13}$ " on or after 1 January $2000[12,20]$. Boilers and gas turbines are not covered by this provision. However, this regulation does not apply to emergency MDEs, lifeboat engines, any device or equipment intended to be used solely for emergencies or to engines installed on ships exclusively engaged in voyages in waters under the sovereignty or the authority of the country whose flag the ship is flying $[16,18,19]$.

The Protocol of 1997 introduced initial NOx emission control levels in 2005 which were applicable to engines installed on the aforementioned ships built before 1 January 2000. The revision of Annex VI in 2008 significantly tightened the NOx emissions allowed by introducing two additional limits of control which apply to MDEs installed on newer ships. These levels of control, known as Tiers, are based on a ship's construction date while the NOx emissions limits, expressed as total weight in $\mathrm{g} / \mathrm{kWh}$, depend on an engine's rated speed. Tier III applies only when ships operates in NOx ECAs. When navigating outside of the ECAs, they must comply with either Tier I or Tier II requirements, depending on the ships' construction date. Therefore, the operation of each MDE to which regulation 13 applies is prohibited, except when the engine NOx emissions are within the Tier limits as presented in Table 1 and Figure 1 which illustrates NOx emission limits at different engine speeds $[17,18]$.

Table 1. MARPOL Annex VI NOx emission limits value [17]

\begin{tabular}{|c|c|c|c|c|}
\hline \multirow[t]{2}{*}{ Tier } & \multirow{2}{*}{$\begin{array}{l}\text { Ship's construction date } \\
\text { (on or after) }\end{array}$} & \multicolumn{3}{|c|}{$\begin{array}{l}\text { Total weighted NOx emission limit value }(\mathrm{g} / \mathrm{kWh}) \\
n=\text { engine's rated speed / crankshaft revolutions per minute }(\mathrm{rpm})\end{array}$} \\
\hline & & $\mathrm{n}<130$ & $\mathrm{n}=130-1999$ & $\mathrm{n} \geq 2000$ \\
\hline I & 1 January 2000 & 17.0 & $45 \cdot n^{-0.2}$ & 9.8 \\
\hline II & 1 January 2011 & 14.4 & $44 \cdot n^{-0.23}$ & 7.7 \\
\hline III & $\begin{array}{l}1 \text { January } 2016^{*} \\
1 \text { January } 2021^{* *}\end{array}$ & 3.4 & $9 \cdot \mathbf{n}^{-0.2}$ & 2.0 \\
\hline
\end{tabular}

*ships operating in the North American or the US Caribbean ECA

Notwithstanding these provisions, regulation 13 also stipulates that the operation of a MDE is permitted when approved by a flag Administration, an exhaust gas cleaning system or when any other equivalent method is implemented to reduce NOx emissions to within the specified limits [21].

Revision of Annex VI in 2008 introduced a retrospective compliance requirement for all ships built between 1 January 1990 and 30 December 1999 that are equipped with MDEs with a power output greater than 5,000 kW and a per cylinder displacement equal or greater than 90 litres, subject to the commercial availability of an Approved Method ${ }^{14}$ to upgrade the engine $[12,17]$.

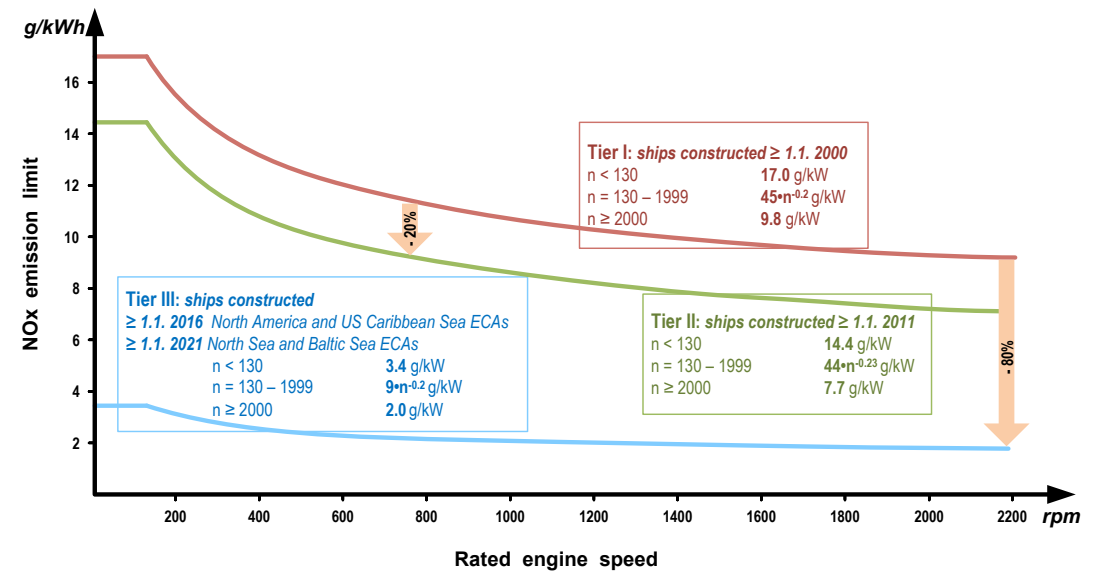

Fig. 1. IMO Annex VI regulation 13 NOx Tier limits

\footnotetext{
${ }^{12}$ Nitrogen oxides (NOx) as compounds contained in the exhaust gases of marine diesel engines are the result of fuel oil combustion. Their emission into the atmosphere affects the formation of smog and contributes to global warming and acid rains. Together with VOCs and other reactive gases in the atmosphere and with the aid of solar radiation, they live airborne particles participate in the creation of ground-level ozone.

${ }^{13}$ A "major conversion" is the phrase which, for the purpose of regulation 13, implies any engine modification that could cause an increment of emissions above the set limits. It is considered as such if the engine is replaced by a new engine manufactured on 1 January 2000 or later, or if any substantial operational or components modification to the engine as defined in NOx Technical Code 2008, e.g. changing camshaft, fuel injection system, air system, combustion chamber configuration, the engine timing calibration, has been made, or if maximum continuous rating of the engine is increased by more than $10 \%$.

${ }^{14}$ Approved Method is method certified by ship's flag Administration for compliance with the Tier I level and must be applied no later than the first renewal survey which occurs more than 12 months after deposition of the advice to IMO. However, if the ship owner can demonstrate that the Approved Method is not commercially available at that time than it is to be installed no later than the next annual survey after which it has become available.
} 
While regulation 13 of Annex VI sets NOx emission limits, the NOx Technical Code $2008^{15}$ (NTC 2008) provides mandatory procedures for the testing, measurement and certification of applicable MDEs that enable their manufacturers, shipowners and flag Administrations to determine engines' compliance with NOx emission standards set forth in this regulation. Current NTC 2008, mandatory provision udder Annex VI, comprises seven chapters and eight appendices [12].

Each, as per the regulation 13 defined MDE must obtain an Engine International Air Pollution Prevention certificate ${ }^{16}$ (EIAPPC) confirming its compliance with the specified NOx emission limits and that it has been tested and inspected in accordance with the requirements of the NTC $2008[12,18]$. In addition, a certification process includes the approval of a Technical File ${ }^{17}$ which is specific to each individual MDE installed on board and which is a record of the engine during its lifetime. Under the NTC 2008 there are three different on board engine verification procedures: engine parameter check method, simplified measurement method and direct monitoring and measurement method. The Engine Technical File contains the one, initially chosen by the engine manufacturer which can in time be changed at the shipowner's discretion. However, as of October 2010, the performance of almost all MDEs is verified using the Parameter check method. All replacements and changes to NOx critical components, settings and operating values are recorded in the Record Book of Engine Parameters which presents the crucial documentation of each MDE [12, 17, 18, 20$]$.

The NTC 2008 testing procedures are different in the case of a new MDE that is to be installed on ship or one that has undergone major conversion. Depending on the NCT 2008 defined conditions, the test for new engines may be carried out on the manufacturer's test bed or upon on board installation. In the second case, the engine manufacturer, shipowner or shipbuilder must submit an application to the flag Administration to perform the test [12]. In addition to the awarding of the individual MDE certification, which is dependent on the approval of the flag Administration, the concepts of Engine Family ${ }^{18}$ or Engine Group ${ }^{19}$ for a series of engines can be implemented in accordance with one or more of the four duty test cycles as specified in appendix II of the Annex VI [12, 17].

Following the IAPP certification requirements, the MDEs are also subject to: an initial survey before IAPPC is issued for the first time or before the ship is put in service, periodical surveys at intervals specified by the flag Administration which cannot exceed five years, an intermediate survey during the period over which the certificate is valid and an annual survey or an unscheduled survey which is enforced by the flag Administration as an alternative to an annual survey [6, $1220]$

\subsection{Regulation 14 - Sulphur oxides and Particulate matter}

The $\mathrm{SOx}^{20}$ and $\mathrm{PM}^{21}$ emissions from ships are controlled by regulation 14 of Annex VI and apply to all MFOs used on board ships. While regulation 13 only covers NOx emissions from MDEs, SOx and PM regulation applies to all MDEs and all other on board equipment, such as boilers, gas turbines, etc., that use MFOs to operate. The sulphur content limits allowed in MFOs, expressed as a percentage of the mass fraction $(\% \mathrm{~m} / \mathrm{m})$, have been progressively reduced over recent years. The current regulation 14 defines the maximum sulphur content allowed in MFOs used on board ships globally and further tightens these limits in designated ECAs, as shown in Table 2 which also includes the dates when the sulphur limit provisions came or are coming into force [7, 12, 22, 23].

Table 2. Current IMO's MFO sulphur limits with enforcement dates [12]

\begin{tabular}{|l|l|}
\hline Global sulphur limits & ECAs sulphur limits \\
\hline $\mathbf{4 . 5 0} \% \mathrm{~m} / \mathrm{m}$ prior to 1 January 2012 & $\mathbf{1 . 5 0} \% \mathrm{~m} / \mathrm{m}$ prior to 1 July 2010 \\
\hline $\mathbf{3 . 5 0} \% \mathrm{~m} / \mathrm{m}$ on and after 1 January 2012 & $\mathbf{1 . 0 0} \% \mathrm{~m} / \mathrm{m}$ on and after 1 July 2010 \\
\hline
\end{tabular}

\footnotetext{
${ }^{15}$ NOx Technical code stands for Technical Code on Control of Emissions of Nitrogen Oxides from Marine Diesel Engines. It was adopted by Resolution 2 on MARPOL Conference in 1997 by as part of Annex VI. It was significantly revised in 2008 at MEPC 58 conference and since then is referred as NOx Technical code 2008 .

${ }^{16}$ Engine International Air Pollution Prevention certificate is issued by flag Administration or by recognised organisation/classification society on its behalf after demonstrating compliance with NOx emission limits and it is a prerequisite for the issuance of IAPPC.

${ }^{17}$ The Technical File is a record containing all details of parameters, including components and settings of an MDE which may influence its NOx emission, all in accordance with NTC 2008 requirements.

${ }^{18}$ The Engine Family concept applies to any series produced MDEs which, through their design are proven to have similar NOx emission characteristics and are used as produced. Also, while during installation on board a ship, they do not require any adjustments or modifications which could adversely affect the NOx emissions.

19 The Engine Group concept may be applied to a smaller series of MDEs produced for similar engine application and which require minor adjustments and modifications during installation or in service. These engines are normally large power engines for main propulsion.

${ }^{20}$ Sulphur oxides (SOx) are a collective name for sulphur dioxides $\left(\mathrm{SO}_{2}\right)$ and sulphur trioxides $\left(\mathrm{SO}_{3}\right)$. These compounds are known as "acidic" gases because its transformation results in the formation of acidic components that separate from the acid rains causing land acidification. They potentially have a detrimental effect on human's health, vegetation and building constructions. They are usually regarded to have a negligible effect on sea $\mathrm{pH}$ far from coastlines because of the seawater alkalinity and their relatively short transportation distances (10-100 km).The SOx emission directly depends on the quality of the MFO, i.e. the sulphur content therein.

${ }^{21}$ Particulate Matter (PM) is a complex mixture of very small particles of soot and ash formed from fuel combustion products and liquid droplets. Additionally, when SOx reaches the atmosphere and forms small aerosol compounds. Most particles form in the atmosphere as a result of complex reactions of chemicals such as sulphur dioxide and nitrogen oxides. The higher the fuel sulphur content, the greater is the particle formation. As they are extremely small, they can be inhaled and cause serious health problems. Particles less than 10 micrometres in diameter pose the greatest problems, because they can get deep into your lungs, and some may even get into your bloodstream.
} 
The IMO commissioned an assessment ${ }^{22}$ to determine whether or not the global oil refinery sector would be able to produce MFOs with $0.50 \% \mathrm{~m} / \mathrm{m}$ sulphur content in sufficient quantities, before deciding whether to introduce this lower limit in 2020 or 2025 . They accounted for trends in global fuel oil markets, the supply and demand for such MFO, demands from other sectors and whether or not the production of these fuels is economically viable in their analyses [15, 24]. On the basis of the audit results, the implementation day for the global $0.50 \% \mathrm{~m} / \mathrm{m}$ sulphur limit will be 1 January 2020 , as per the MEPC.280(70) resolution which was adopted on 28 October 2016 [25]. Figure 2 illustrates the IMO's progressive reduction of the sulphur content in MFOs over time. The enforcement dates and estimated percentage reduction in overall SOx emissions from ships are also included.

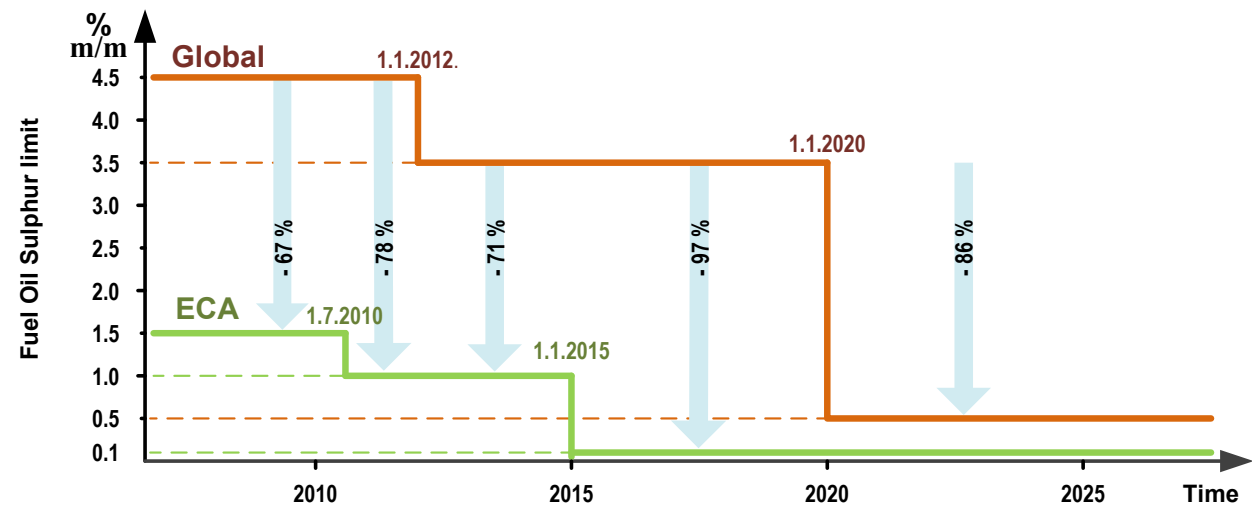

Fig. 2. MARPOL Annex VI regulation 14 - sulphur limits for MFOs [26]

Regulation 14 states that for ships to comply, they must have written on board procedures which detail how to perform the MFO change to enable them to use MFO of differing sulphur content for navigation and operation within and outside the ECAs. This procedure must allow sufficient time for the fuel delivery system to completely flush out all the MFO with sulphur content higher than that permitted for operation within the ECA before the ship enters into it. The date, time and position of the ship after the completion of any such fuel oil change over procedure must be recorded in the logbook prescribed by the flag Administration along with the volume of low sulphur fuel in each tank, either prior to entering the ECA, or to the commencement of such an operation on leaving the ECA area $[17,20]$.

In addition, one of the controlling instruments of bunkered MFO sulphur content and quality is regulation 18 of Annex VI that contains provisions primarily related to MFOs suppliers and which can be considered to support regulations 13 and 14 regarding aspects beyond the control of the shipowner. This regulation stipulates that the details of each MFO delivered for combustion on board ships must be specified in the Bunker Delivery Note ${ }^{23}$ accessible for inspection at all times [12].

Another potential means to comply with emission control requirements, subject to approval by the flag Administration, may be accepted as per Annex VI regulation 4. Any relevant IMO guidelines developed for approving such methods should be taken into account. An exhaust gas cleaning system known as "scrubber" is such a method for which the MEPC.259(68) guidelines have been adopted. This system is called a secondary control method, since the SOx pollutants have already been formed but are subsequently, partially removed by exhaust gas washing water prior to discharge into the atmosphere. This allows high sulphur MFOs to be used if a system performs within acceptable limits as approved by the flag Administration [12, 17].

\subsection{Emission Control Areas}

An ECA is a specific sea area, including port areas, designated by the IMO in accordance with criteria and procedures set forth in appendix III to Annex VI, in which more stringent emission regulations have been established. For the purpose

\footnotetext{
22 An assessment of the availability of MFOs was conducted by CE Delft, independent research and consultancy organisation which specialises in developing innovative solutions to environmental problems. The study considered the estimated demand for MFOs in 2020 based on the fuel consumption of ships in 2012, the projected increase in energy demand, the use of alternative compliance options such as Exhaust Gas Cleaning Systems and LNG. The main result of the study was that for all scenarios the refinery sector has the capability to supply sufficient quantities of MFOs with a sulphur content limited to $0.50 \% \mathrm{~m} / \mathrm{m}$ or less and $0.10 \% \mathrm{~m} / \mathrm{m}$ or less to meet the predicted demand for these products, while also meeting demand for non-MFOs.

${ }^{23}$ Bunker Delivery Note is a document certifying that the MFO delivered to the ship is in accordance with the requirements of Annex VI Resolution MEPC.176 (58) which has to be kept on board for a minimum of three years. It must include: name and IMO number of receiving ship, MFO loading port, date of delivery, name, address and telephone number of MFO oil supplier, delivered MFO product name, quantity in metric tons, density at $15^{\circ}$ $\mathrm{C}, \mathrm{kg} / \mathrm{m}^{3}$, sulphur content in $\% \mathrm{~m} / \mathrm{m}$ and a signed and certified declaration by MFO supplier's representative that the supplied product is in accordance with the applicable requirements of Annex VI regulations 14 and 18.
} 
of regulation 13 Tier III emission standards and regulation 14 requirements on SOx emissions limits, there are currently four designated ECAs, as presented in Table 3 which includes adoption, enforcement and effective from dates. The Baltic Sea ECA is defined in MARPOL Annex I, while the North Sea ECA is defined in Annex V. The North American and US Caribbean Sea ECA are detailed in appendix VII to Annex VI [16, 20, 27]. As is apparent from Table 3, the North American and US Caribbean Sea ECAs cover SOx and PM while European ECAs relate only to SOx emissions.

While SOx restrictions are already applicable in all ECAs for all ships, a NOx ECA Tier III standard applies only on new ships built on or after Annex VI defined dates as indicated in Table 3. The latest resolution related to the ECAs was the MEPC.286(71) which was adopted on 7 July 2017 and which designated the Baltic Sea and the North Sea ECAs for NOx Tier III control [16, 20].

Table 3. MARPOL Annex VI ECAs adoption, enforcement and effective from dates of controlled pollutants [27]

\begin{tabular}{|l|c|c|c|c|}
\hline \multicolumn{1}{|c|}{ ECAs } & $\begin{array}{c}\text { Controlled } \\
\text { compounds }\end{array}$ & Adopted by IMO & Entry into force & Effective from \\
\hline \multirow{2}{*}{ Baltic Sea area } & SOx & 26 Sept 1997 & 19 May 2005 & 19 May 2006 \\
\hline \multirow{2}{*}{ North Sea area } & NOx & 7 Jul 2017 & 1 Jan 2019 & 1 Jan 2021* \\
\hline \multirow{2}{*}{ North American Sea area } & SOx & 22 Jul 2005 & 22 Nov 2006 & 22 Nov 2007 \\
\cline { 2 - 5 } & NOx & 7 Jul 2017 & 1 Jan 2019 & 1 Jan 2021* \\
\hline \multirow{2}{*}{ US Caribbean Sea area } & NOx PM & 26 Mar 2010 & 1 Aug 2011 & 1 Aug 2012 \\
\cline { 2 - 5 } & SOx; PM & 26 Mar 2010 & 1 Aug 2011 & 1 Jan 2016* \\
\hline
\end{tabular}

* In effect for NOx Tier III compliant ships built on or after this date

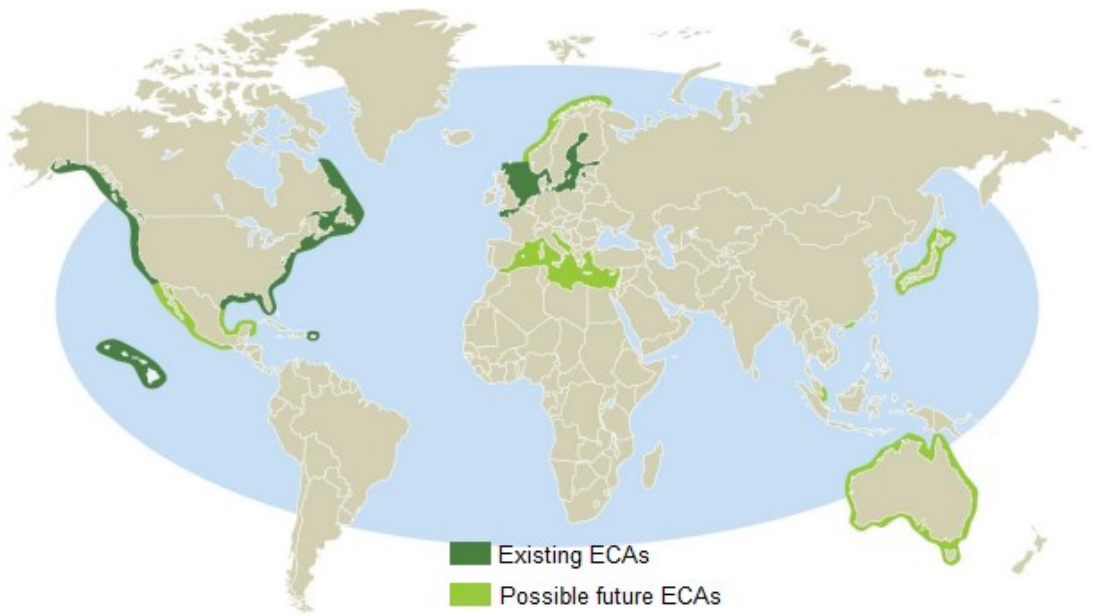

Fig. 3. Present and possible future ECAs [28]

\subsection{Chapter 4 - Regulations on energy efficiency for ships}

The Kyoto Protocol recognised and acknowledged that greenhouse gas ${ }^{24}$ (GHG) emissions from ships cannot be attributed to any particular country or economy due to the complex international nature of the shipping industry. In response, the MEPC 62 session held in July 2011, amended Annex VI with Resolution MEPC.203(62) and a new chapter 4 was introduced which includes regulations to control the energy efficiency of ships. These regulations imply a number of mandatory, cost effective, operational and technical measures for various ship types which are responsible for approximately $85 \%$ of GHG emissions, primarily $\mathrm{CO}_{2}$ which is the most significant GHG effect contributor. They also represent the first mandatory, legally binding regime to reduce global $\mathrm{CO}_{2}$ emissions from an entire industry sector [5, $29,30]$.

\footnotetext{
${ }^{24}$ Greenhouse gases (GHG) form an air thermal wrap around the Earth that prevents the loss of heat energy into space and also provides favourable climatic conditions for life. Earth reflects $70 \%$ of solar radiation due to its surface, and $\mathrm{GHG}$ in the atmosphere $\left(\mathrm{CO}_{2}, \mathrm{H}_{2} \mathrm{O}, \mathrm{CH}_{4}, \mathrm{~N}_{2} \mathrm{O}\right)$ absorbs part of that radiation, resulting in atmospheric warming, called the greenhouse effect which maintains a favourable climate for all living beings. Human activity, in particular the emission of $\mathrm{CO}_{2}$, a combustion product of fossil fuels, is the biggest contributor to the increase in the unnatural concentration of greenhouse gases in the atmosphere. Some chlorofluorocarbons from refrigeration devices also fall into this category.
} 
Chapter 4 came into force on 1 January 2013. It has been amended over the years, to contain regulatory provisions, including guidelines which were further developed to assist in the implementation of the regulations. It currently comprises six regulations and 13 related guidelines which apply to all internationally trading ships of 400 GT and more $[12,21]$.

The main technical measure of compliance with the regulations is the Energy Efficiency Design Index ${ }^{25}$ (EEDI) which is a performance based mechanism for a new ship or one which has undergone a major conversion and represents its minimum required energy efficiency calculated using an IMO developed formula [29]. It is left to the ship designers and builders' discretion to choose adequate and cost effective technologies the ship to comply with the Attained EEDI ${ }^{26}$ which has to be equal to or less than the Required EEDI ${ }^{27}$ [12]. This mechanism includes a schedule which sets out stringent $\mathrm{CO}_{2}$ emission levels for every five years period, as outlined in Figure 4. This progressive measure continuously stimulates technical development and component innovation and provides an incentive s to improve ship's energy efficiency [29, $31,32]$. However, IMO is in progress of reviewing the status of technological developments and, if proven necessary, will amend the time periods and the EEDI reference line parameters for relevant ship types as well as the reduction rates set out in this regulation [33].

The Ship Specific Energy Efficiency Plan (SEMP) is a second crucial measure which is required by regulation 22 for existing and new ships of 400 GT and above, with the purpose of establishing operational mechanisms in terms of fuel efficiency to improve ship's energy efficiency performance. It also provides an approach for shipping companies to manage the entire fleet efficiency over the time by incorporating a number of operational management tools such as: improved voyage planning, speed and power optimization, optimized ship handling, improved fleet management, improved cargo handling, energy management and monitoring tools like Energy Efficiency Operational Indicator ${ }^{28}$ (EEOI) $[15,29,33]$. The SEEMP should be developed as a ship-specific plan and adjusted to the needs of individual companies by taking into account relevant guidelines ${ }^{29}$ adopted by IMO. It is not subject to approval by the flag Administration. However, it must be on board before the issuance of the first International Energy Efficiency certificate (IEEC) which is required as per Annex VI chapter 2 requirements. Its form if provided as appendix VIII to this Annex 12].

The latest significant milestone in the consistent reduction of GHG emissions from ships by IMO is a new mandatory requirement, adopted by MEPC 70 on 28 October 2016. Amendments to chapter 4 of Annex VI, which came into force on 1 March 2018, introduced new Regulation 22A on the Collection and Reporting of Ship Fuel Oil Consumption Data. These monitoring requirements obligate ships of 5,000 GT and more to collect consumption data for each type of fuel oil that they use. They also include provisions for flag States in relation to data collection, surveys and certification. The amendments also encompass two new related appendices to Annex VI. These newly enforced regulations will enable a global centralised database to be established which will enable more accurate analyses to be performed and inform the decision making process $[14,34,35]$.

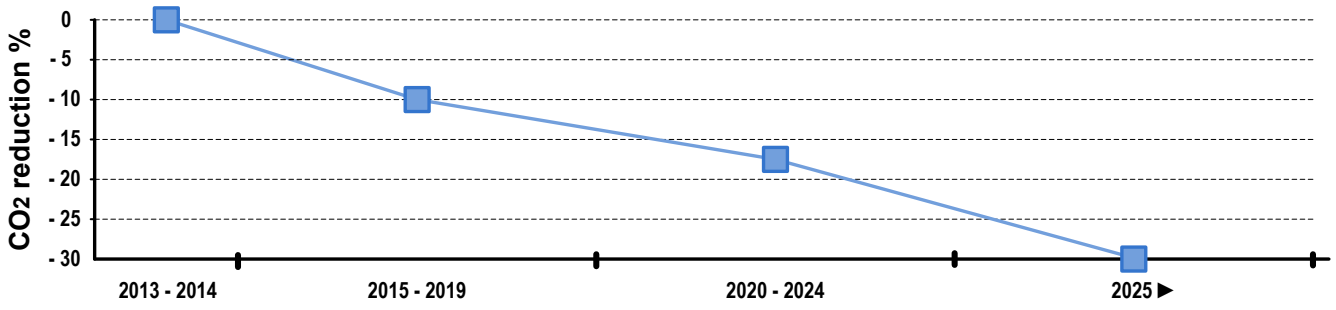

Fig. 4. $\mathrm{CO}_{2}$ reduction based on EEDI implementation phases [31]

\section{Conclusion}

Since air pollution has been scientifically proven to negatively impact climate change, and has become a serious global issue, emissions of harmful pollutant gases from land based sources gradually started to be regulated and reduced. As a

\footnotetext{
25 The Energy Efficiency Design Index (EEDI) provides a specific figure for an individual ship design expressed in grams of $\mathrm{CO}_{2}$ per tonne mile $(\mathrm{g} / \mathrm{t} \cdot \mathrm{nm})$. The smaller the EEDI, the more energy efficient is the ship design. It is calculated using a formula based on the technical design parameters for a given ship.

${ }^{26}$ The Attained EEDI calculation is specific to each ship type as defined in Annex VI regulation 2 and it is performed by the method specified in the latest amended MEPC.281(70) guidelines. The Attained EEDI indicates the estimated energy efficiency performance of the ship and has to be accompanied by the EEDI technical file that contains all the information necessary to be able to calculate the Attained EEDI and which also shows the process of calculation. It must be verified, based on the EEDI technical file, by the flag Administration.

${ }^{27}$ The Required EEDI must be greater than, or equal to the Attained EEDI. Its calculation depends on X - correction factor (\%) specified for each ship type and size and which represents the EEDI relative to the EEDI reference line given in Table 2 of the same regulation.

${ }_{28}$ The Energy Efficiency Operational Indicator (EEOI) is a monitoring tool which enables operators to measure the fuel efficiency of a ship in operation and to gauge the effect of any operational changes, e.g. improved voyage planning or more frequent propeller cleaning, or the introduction of technical measures such as waste heat recovery systems or a new propeller.

${ }^{29}$ New 2016 Guidelines for the Development of a Ship Energy Efficiency Management Plan were adopted on 28 October 2016 and include the Ship Fuel Oil Consumption Data Collection Plan as the new provision of the SEEMP.
} 
result, focus has turned to air pollution from international shipping which accounts for $90 \%$ of total world trade, and is undoubtedly a significant contributor to global atmospheric pollution.

Hence, under the IMO initiative, 26 of September 1997, the MARPOL Convention was revised and amended with the 1997 Protocol. A new Annex VI was introduced which included rules regulating the emission of air pollutants from ships, with a particular emphasis on emissions of NOx, SOx and ODS. It is important to emphasize that, after the regulations came into force, objective flexibility was applied to parameters such as the inertness of fleet renewal, the average age of a ship as well as the adaptation of MDEs, systems and equipment in existing ships.

Following on from the adoption of Annex VI, further research into air pollutants informed additional amendments, and resulted in the adoption of new regulations and certificates. The most significant example was the introduction of chapter IV and its role in reducing $\mathrm{CO}_{2}$ emissions from ships, the last remaining significant atmospheric pollutant to be controlled. The IAPP certificate is a crucial document that verifies a ship's compliance with Annex VI regulations. Annex VI is still a work in progress, a regulatory provision which continues to be enhanced with new regulations and more stringent revisions to existing ones.

Shipowners and other relevant stakeholders in the international maritime industry have to accept the fact that stringent rules regulating emissions of atmosphere pollutants from ships are enforceable and are not optional. They represent important preconditions and obligations to the international maritime industry and have to be complied with.

The introduction of these regulations has had a significant effect on both, MDEs manufacturers and marine fuel oil suppliers. Furthermore, they require shipowners to be more involved in ensuring that the necessary operative procedures are in place, are correctly implemented and effectively applied, both on ships and in companies' offices ashore.

$90 \%$ of merchant ships on international voyages use MDEs as their prime mover whose resultant exhaust gases are a major contributor to air pollution. Therefore, to maintain MDEs as the prime and the most efficient propulsion engine in use, it is imperative for manufacturers to work intensively to seek out new technological solutions and alternatives to further reduce harmful emissions and to comply with increasingly stringent air pollution regulations. New knowledge gained through future research will enable existing propulsion systems to be more efficiently altered to meet ecological demands.

\section{References}

1. Marine Environment, International Maritime Organization, Available: http://www.imo.org/en/OurWork/ Environment/Pages/Default.aspx (March 2018)

2. Air pollution from ships, Clean Shipping Coalition (2011), Available: http://www.cleanshipping.org/download /111128_Air\%20pollution\%20from\%20ships_New_Nov-11(3).pdf (March 2018)

3. Shipping sector cuts nitrogen loads to the Baltic Sea, HELCOM (2016), Available: http://www.helcom.fi/news /Pages/Shipping-sector-cuts-Nitrogen-loads-to-the-Baltic-Sea.aspx (March 2018)

4. Development of a Methodology to Measure and Asses Shi Emissions, Australian Maritime College, IAMU 2015 Research Project (No. 20150202) (2016), Available: https:/gmn.imo.org/wp-content/uploads/2017/10/20150202 AMC_measure-and-assess-ship-emissions.compressed.pdf (March 2018)

5. Third IMO GHG Study 2014, Executive Summary and Final Report (2015), International Maritime Organization, Available: https://gmn.imo.org/wp-content/uploads/2017/05/GHG3-Executive-Summary-and-Report_web.pdf, (March 2018)

6. M. Anantharaman, V. Garaniya, F. Khan, B. Lewarn: Marine Engines and their Impact on the Economy, Technical Efficiency and Environment, JIME Vol. 50, No. 3 (2015), Available: https://www.researchgate.net /publication/310666162_Marine_Engines_and_their_Impact_on_the_Economy_Technical_Efficiency_and_Enviro nment (March 2018)

7. B. Milošević Pujo, N. Jurjević: Onečišćenje mora iz zraka emisijom ispušnih plinova, NM 51 (5-6), p.p. 178-184, Međunarodni znanstveno-stručni časopis za more i pomorstvo, Dubrovnik, (2004), Available: https://hrcak .srce.hr/index.php?show=clanak\&id_clanak_jezik=12802\&lang=en (March 2018)

8. Status of Treaties, International Maritime Organization, Available: http://www.imo.org/en/About/Conventionsb /StatusOfConventions/Documents/StatusOfTreaties.pdf (March 2018

9. Introduction to IMO, International Maritime Organization, Available: http://www.imo.org/en/About/Pages/ Default.aspx (March 2018)

10. Focus on IMO, MARPOL - 25 years, International Maritime Organization (1998), Available: http://www.imo.org /en/KnowledgeCentre/ReferencesAndArchives/FocusOnIMO(Archives)/Documents/Focus\%20on\%20IMO\%20-\% 20MARPOL\%20-\%2025\%20years\%20(October\%201998).pdf (March 2018)

11. MARPOL 73-78 Briefhistory - list of amendments to date and where to find them, International Maritime Organization, Available: http://www.imo.org/en/KnowledgeCentre/ReferencesAndArchives/HistoryofMARPOL/ Documents/MARPOL73-78Brief History-ListOfAmendmentsAndHowToFindThem.htm (March 2018)

12. MARPOL Annex VI and NTC 2008 with guidelines for implementation 2017 edition, International Maritime Organization (2017)

13. Annex VI of MARPOL 73/78 - Regulations for the Prevention of Air Pollution from Ships, Insight 176 Gard AS, Arendal, Norway (2004), Available: http:/www.gard.no/web/updates/content/53059/annex-vi-of-marpol-7378regulations-for-the-prevention-of-air-pollution-from-ships (March 2018) 
14. Module 1 - Climate Change and the Shipping Response, IMO Train the Trainer (TTT) Course on Energy Efficient Ship Operation, International Maritime Organization (2016), Available: http://www.imo.org/en/OurWork /Environment/PollutionPrevention/AirPollution/Documents/Air\%20pollution/M1\%20Climate\%20change\%20and\% 20shipping\%20response\%20final.pdf (March 2018)

15. Hughes, E.: MARPOL Annex VI - an update of international regulatory developments for prevention of air pollution and the energy efficiency of ships, Global Shippers' Forum AGM, Colombo, Sri Lanka (2016), Available: https://globalshippersforum.com/media/1252/edmund-hughes-imo-29-july-2016_final.p (March 2018)

16. MARPOL Consolidated Edition 2017, International Maritime Organization, London, UK, (2017)

17. MARPOL How to do it 2013 Edition, International Maritime Organization, London, UK, (2011)

18. MARPOL 73/78 Annex VI - Regulations for the prevention of Air Pollution from ships - Technical and Operational implications, Det Norske Veritas, Available: http://hulpinnood.nl/wp-content/uploads/2015/03/BIJLAGE3_Marpolannex-VI.pdf (March 2018)

19. M. Yamasaki: MARPOL Annex VI Regulations - Prevention of Air Pollution from Ships, TRACECA Regional Seminar on MARPOL Awareness and Implementation, Moldova (2015), Available: http://www.tracecaorg.org/fileadmin/fmdam/TAREP/68ta/1/Session_8_MY_MARPOL_Annex_VI_chapters_1_to_3_and_Black_ Carbon_Final.pdf (March 2018)

20. MARPOLL 73/78, Regulations for the Prevention of Air Pollution from Ships Annex VI, Autoridad Marítima de Panamá, Available: http://amp.gob.pa/amp/asi/online\%20course\%20module/MODULE\%208A.pdf (March 2018)

21. I. Djadjev: How to comply with, MARPOL 73/78, DOI: 10.13140/RG.2.1.4715.7922 (2015), Available: https://www.researchgate.net/publication/277708775_Complying_with_MARPOL_7378, (March 2018)

22. IMO and the Environment, International Maritime Organization, Available: http://www.imo.org/en/OurWork /Environment/Documents/IMO\%20and\%20the\%20Environment\%202011.pdf (March 2018)

23. Particulate Matter (PM) Pollution, United States Environmental Protection Agency, Available: https://www.epa. gov/pm-pollution (March 2018)

24. J. Faber, S. Ahdour, M.'t Hoenet, et. al.: Assessment of Fuel Oil Availability Final report, Publication code: 16.7G68.71, CE Delft (2016) Available: http://www.imo.org/en/OurWork/Documents/MEPC\%2070-INF.6\%20\% 20Assessment $\% 20$ of\%20fuel\%20oil\%20availability.pdf (March 2018)

25. RESOLUTION MEPC.280(70), Effective Date of Implementation of the Fuel Oil Standard in Regulation 14.1.3 of MARPOL Annex VI, MEPC 70/18/Add.1, International Maritime Organization (2016), Available: http://www.imo. org/en/OurWork/Environment/PollutionPrevention/AirPollution/Documents/280\%2870\%29.pdf (March 2018)

26. Almeida R.: Have the IMO and the International Chamber of Shipping Overlooked the Obvious? (2012), Available: http:/gcaptain.com/international-chamber-shipping/\#.VfaXak-9S71 (March 2018)

27. Special Areas under MARPOL, International Maritime Organization, Available: www.imo.org/en/OurWork /Environment/SpecialAreasUnderMARPOL/Pages/Default.aspx (March 2018)

28. Gard: Annex VI of Marpol 73/78 - Regulations for the Prevention of Air Pollution from Ships, Insight 176, Gard (2004), Available: http:/www.gard.no/web/updates/content/53059/annex-vi-of-marpol-7378-regulations-for-theprevention-of-air-pollution-from-ships (March 2018)

29. Energy Efficiency Measures, International Maritime Organization, Available: http://www.imo.org/en/OurWork/ Environment/PollutionPrevention/AirPollution/Pages/Technical-and-Operational-Measures.aspx (March 2018)

30. Učinak staklenika, Croatian Ministry of Environment and Nature protection, Available: http://klima.mzoip.hr /default.aspx?id=4 (March 2018)

31. J-F Helfre, P. A. Couto Boot: Emission Reduction in the Shipping Industry: Regulations, Exposure and Solutions, Sustainalytics (2013), Available: http://www.sustainalytics.com/sites/default/files/shippingemissions_july2013.pdf (March 2018)

32. E. Hughes: A new chapter for MARPOL Annex VI-requirements for technical and operational measures to improve the energy efficiency of international shipping, International Maritime Organization, London, UK, February (2013), Available: $\quad$ http:/www.imo.org/en/KnowledgeCentre/PapersAndArticlesByIMOStaff/Documents/ A\%20new\%20chapter\%20for\%20MARPOL\%20Annex\%20VI\%20-\%20E\%20Hughes.pdf (March 2018)

33. Module 2: Ship Energy Efficiency Regulations and Related Guidelines, IMO Train the Trainer Course, International Maritime Organization, Available: http:/www.imo.org/en/OurWork/Environment/PollutionPreven tion/AirPollution/Documents/Air\%20pollution/M2\%20Energy\%20Efficiency\%20Regulations\%20\%20IMO\%20TT T \%20course\%20presentation\%20final1.ppt (March 2018)

34. List of amendments expected to enter into force this year and in the coming years, International Maritime Organization, Available: http://www.imo.org/en/About/Conventions/Pages/Action-Dates.aspx (March 2018)

35. New requirements for international shipping as UN body continues to address greenhouse gas emissions, International Maritime Organization (2016), Available: http://www.imo.org/en/MediaCentre/PressBriefings/Pages /28-MEPC-data-collection--.aspx (March 2018)

36. H. Wang: Cutting carbon from Ships, The International Council On Clean Transportation (2012), Available: https://www.theicct.org/blogs/staff/cutting-carbon-ships (March 2018) 